\title{
FORMAÇÃO DE PROFESSORES E POLÍTICAS CURRICULARES NA EDUCAÇÃO SUPERIOR: UM DEBATE SOBRE A DELIMITAÇÃO DO CAMPO DE CONHECIMENTO
}

\author{
Walter STROBEL NETO* e Maria de Lourdes Pindo de ALMEIRA** \\ Universidade do Oeste de Santa Catarina \\ walstrobel@gmail.com*
}

Submetido 30/03/2016 - Aceito 23/03/2017

DOI: $10.15628 /$ holos.2017.4353

\begin{abstract}
RESUMO
Este texto é fruto de uma pesquisa realizada no mestrado em Educação da UNOESC-SC que analisa as tendências curriculares na visão dos professores do curso de Pedagogia. O objetivo desta produção é apresentar o Estado da Arte que tem como categorias que norteiam a investigação: Políticas Curriculares, Formação de Professores, Políticas Educacionais e Formação do Pedagogo. A pesquisa foi financiada pelo Fundo de Amparo à Pesquisa da Unoesc - Fape Unoesc, e está vinculada a um projeto macro da Rede Iberoamericana de Politicas e Processos em Educação Superior Unoesc Unicamp. Este estudo auxilia investigações que tem como base discussões sobre políticas publicas de formação de professores, por meio de um levantamento e debate junto a autores especialistas no tema, tais como Pereira (1999), Libâneo (2006), Aguiar et. al. (2006), Scheibe (2007), Scheider (2010), Gatti (2013), Casagrande (2014) entre
\end{abstract}

outros. A metodologia utilizada foi a pesquisa bibliográfica e documental, tendo como fundamentação teorica a análise dos textos encontrados no Estado da Arte realizado no site do Scielo, Capes teses e dissertações e Capes Periódicos. Este debate entre os diversos autores contribuiu para uma possivel delimitação do campo do conhecimento cientifico. A análise do objeto da pesquisa pelo que foi encontrado nos sites cientificos, apresentou como resultado parcial, uma enorme e evidente manipulação de agências financiadoras internacionais e do Estado Liberal brasileiro, sobre as políticas construidas a partir de interesses voltados ao mercado capitalista. Estas imposições podem ser percebidas nas Diretrizes Curriculares da maioria da educação superior brasileira, hora privilegiando a pedagogia técnica, ora impondo ajustes não contributivos para áreas de formação como é o caso das Licenciaturas.

PALAVRAS-CHAVE: Políticas de Educação Superior; Políticas de Formação de professores; Pedagogia.

\section{TEACHER TRAINING AND CURRICULUM POLICIES IN HIGHER EDUCATION: A DEBATE ON THE KNOWLEDGE OF THE FIELD LIMITS}

\begin{abstract}
This text is the result of a survey conducted in the Masters in UNOESC-SC Education analyzing the curricular trends in the vision of the Faculty of Education teachers. The purpose of this production is to present the State of the Art whose categories that guide the research: Curriculum Policies, Teacher Education, Educational Policy and Training Educator. The research was funded by the Support Fund to search Unoesc - Fape Unoesc, and is linked to an Iberoamerican Network macro project Policies and Processes in Higher Education Unoesc Unicamp. This study supports research that is based on discussions of public policy teacher training, through a survey and discussion with experts authors on the subject, such as Pereira (1999), Libâneo (2006), Aguiar et. al. (2006) Scheibe (2007), Scheider (2010), Gatti (2013), Casagrande (2014) among
\end{abstract}

others. The methodology used was the bibliographical and documentary research, having as theoretical basis the analysis of the texts found in the State of the Art held at the Scielo site, Capes theses and dissertations and Capes. This debate between the different authors contributed to a possible delimitation of the scientific knowledge field. The analysis of the research object for what was found in scientific sites, presented as a partial result, a huge and obvious manipulation of international funding agencies and the Brazilian State Liberal, built on policies from interests on the capitalist market. These taxes can be perceived in the Curriculum Guidelines of the majority of Brazilian higher education, time favoring technical pedagogy, sometimes imposing non-contributory adjustments to training areas such as the Undergraduate. 


\section{INTRODUÇÃO}

O acesso à educação no Brasil apresenta uma relação muito dependente aos interesses do Estado, pois sempre existem forças externas que direcionam o rumo de nosso País, interessadas na manipulação e manutenção de um estado Capitalista e Neoliberal, onde o capital exerce o poder, e consequentemente, dita as regras para uma conduta e acesso ao que tange a educação, pois esta é importantíssima no processo de submissão entre as nações, e é por meio que se consegue libertar ou aprisionar uma população. Neste processo, o interesse posto para o momento é o de educar para o trabalho, construindo um futuro de mão de obra especializada para o trabalho dentro das indústrias, por meio de programas sociais focados na escolarização técnica.

Estas orientações são construídas por entidades que "auxiliam" o financiamento das nações, dentro ações que direcionam esta nação para o que é de interesse da entidade, como o auxílio do Banco Mundial e do Fundo Monetário Internacional. Estas instituições são "parceiras" do Brasil e "auxiliam" a organizar a educação brasileira, por meio de documentos orientadores referentes à educação. Neste sentido, a educação não é construída pelos envolvidos no processo, por meio de várias visões e necessidades, exemplos e vivências, mas sim por regras impostas, excluindo o debate na educação.

Os mecanismos utilizados para tais atos são propostos por leis, fundos, diretrizes e planos nacionais, que organizam o sistema de controle do processo. Um exemplo é a Ementa Constitucional 14/96, Artigo 60 da Lei 9394 de 20/12/1996, que fixa as Diretrizes e Bases da Educação Nacional, onde é interessante observar a vinculação entre educação escolar, trabalho e práticas sociais. Outro exemplo é a criação de fundos com porcentagens mínimas préestabelecidas de investimento das várias esferas de governo.

É desta maneira que a Escola, que deveria ser o local onde se promovem a cultura, a socialização, a liberdade, é prejudicada pelo controle do Estado e este de seus financiadores externos, instalando-se uma falta de liberdade e autonomia.

Diante deste contexto histórico decidimos estudar as Políticas de Educação Superior e a Formação de Professores, focados no contexto do curso de Pedagogia, por meio de um levantamento e debate, a fim de discutir a produção acadêmica bibliográfica contemporânea, por meio da construção de um Estado da Arte, que visa levantar e discutir um conjunto de conhecimentos nos diferentes campos do conhecimento, a fim de perceber que dimensões estão sendo estudadas e quais as características relacionam-se quanto às publicações científicas, como anais de congressos e seminários, artigos em periódicos e comunicações, dissertações de mestrado e teses de doutorado.

Esta investigação está vinculada à Rede Iberoamericana de Politicas e Processos em Educação Superior Unoesc Unicamp, ao Grupo de Estudos e Pesquisas em Políticas de Educação Superior da Região Sul - GEPES SUL, que faz parte do GiEPES - Grupo Internacional de Estudos e Pesquisas em Educação Superior da UNICAMP. É uma pesquisa financiada pelo Fundo de Amparo à Pesquisa da Unoesc - Fape Unoesc.

A investigação que deu base a este debate está sendo desenvolvida no mestrado da UNOESC-SC e tem como objetivo desvelar quais ênfases devem, na opinião dos professores, ser priorizadas para que a formação do estudante responda aos imperativos do tempo presente e do futuro próximo. O problema de pesquisa que norteou a pesquisa foi quais são as tendências curriculares apresentadas na visão dos professores do curso de Pedagogia da UNOESC, em seus diferentes campi, de 2005 a 2015? Nossa pretensão nesta produção escrita é demonstrar o que 
foi encontrado no Estado da Arte realizado tendo como eixos temáticos norteadores: Políticas Curriculares, Formação de Professores, Políticas Educacionais e Formação do Pedagogo.

O Estado da Arte possui dois momentos, um, primeiro, que é aquele em que ele interage com a produção acadêmica através da quantificação e de identificação de dados bibliográficos, com o objetivo de mapear essa produção num período delimitado, em anos, locais, áreas de produção... Um segundo momento é aquele em que o pesquisador se pergunta sobre a possibilidade de inventariar essa produção, imaginando tendências, ênfases, escolhas metodológicas e teóricas, aproximando ou diferenciando trabalhos entre si, na escrita de uma história de uma determinada área do conhecimento. (Ferreira (2002, p. 265)

Faz-se necessário estudar estas relações, desvelando as atrocidades que se impõem à sociedade, com o intuito de manipulação e controle de nações. As políticas educacionais e as pesquisas em políticas educacionais devem ser independentes, pois não podem ser influenciadas por organismos proprietários de interesses. Estas pesquisas tem que construir conhecimentos que contribuam para um crescimento social significativo para população, servindo de subsídio, auxiliando nas formulações ou combatendo legislações educacionais, e não direcionarem expectativas e resultados manipulados para posteriores tomadas de decisão pré-estabelecidas conforme algum interesse.

Compreendemos que os intelectuais são formados por um conjunto de forças atuantes, e que desta forma caracterizam uma forma de hierarquização, subordinação e emancipação, promovendo um conflito e consequentemente movendo o debate, por meio da construção e observação dos fatos com olhares distintos. Assim, as pesquisas construirão para Almeida (2015, p.32) "as políticas educacionais que afetam a formação de trabalhadores e dirigentes nas instituições governamentais e civis."

Assim, esta pesquisa visa debater entre várias outras pesquisas, o conjunto de conhecimentos de diferentes autores para uma concreta visualização da realidade.

Justifica-se também a pesquisa por meio de estudos acadêmicos, no qual a Universidade é responsável pela divulgação e unificação de ideologia, onde a sociedade civil é campo de luta hegemônica. Desta maneira, os intelectuais, que se encontram na sua maioria dentro das Instituições de Educação Superior, são os agentes que irão trabalhar com estas pesquisas em políticas educacionais, contribuindo para a vontade coletiva, ou não.

Neste estudo, a inserção da discussão sobre o Estado é necessária, pois como apresentado, este exerce diretamente funções econômicas e ideológicas. Diante do explanado, é perceptível que vivemos em uma sociedade regulada e praticamente sem classes, pois o Estado é um representante manipulado da classe dominante. Na situação atual posta, o capital monopoliza a cultura, ciência, arte, Universidade, intelectuais, pesquisa, onde o cenário deveria ser contrário, a Universidade revolucionária e independente.

A Universidade tem por papel ético poder construir conhecimentos que possibilitem uma discussão entre as estruturas, setores, e que contribua com conhecimentos independentes e não influenciados, sem tendências de mercado ou interesses. Para Almeida (20015, p.39) "as investigações das políticas educacionais não podem ser dissociadas do estudo sobre o Estado".

Frente ao breve exposto, a discussão e percepção sobre a formação de professores é de suma importância, pois são estes que irão construir por meio da Educação e de suas políticas públicas as gerações futuras, discutindo, pesquisando e debatendo.

Os cursos de formação de professores vêm sofrendo inúmeras transformações no que tange as novas exigências das leis e diretrizes curriculares, aonde as propostas vão desde reestruturação de cursos até a possibilidade de o trabalho docente ser por competências. A 
ênfase da discussão tem estado centrada, em grande parte, nos currículos dos cursos de formação de professores. No cenário educacional brasileiro essa temática ganha repercussão, através da discussão sobre as reformulações curriculares dos cursos de formação docente.

Atualmente a universidade se pergunta qual é o seu papel: formar o profissional para os diferentes campos da atividade humana segundo os interesses do mercado de trabalho ou preparar os estudantes para desempenhar atividades profissionais no mundo do trabalho, preparando-os para exercer papel social de cidadãos-profissionais que contribuam para o desenvolvimento de uma sociedade mais humana e ética. A Universidade se encontra dividida entre os critérios da ética e os critérios do mercado capitalista.

Esta pesquisa faz parte de uma investigação que propõe estudar, dentro da área de concentração Políticas de Formação de Professores, as tendências curriculares na visão dos professores do curso de Pedagogia dos diferentes campi da Universidade do Oeste Catarinense nesta segunda década do século XXI. Segundo Connor (1992), a concepção que se tem de algo, determina uma direção para a sua consecução, portanto, a concepção que se tem de currículo leva ao direcionamento da ação pedagógica com significativa consequência sobre a formação do estudante e futuro profissional.

Por meio da construção de um inventário de produções, o Estado da Arte auxiliará a análise e a descrição das metodologias correlacionadas sobre o tema que se busca estudar, por meio das categorias, temas e fenômenos em cada conjunto de trabalhos analisados. Este levantamento embasará o hall de conhecimentos já construídos, auxiliando na maturidade e inovação do tema proposto. Identificar e estudar o que é contemporâneo são processos relevantes, a fim de contribuir ao conjunto de olhares sobre pesquisa, principalmente no que tange a pesquisa em educação no Brasil com foco na educação superior.

Para a realização do Estado da Arte foram pesquisadas publicações de estudos científicos em dois reconhecidos bancos de dados virtuais, sendo os portais Scielo ${ }^{1}$ e Capes Periódicos ${ }^{2}$. Em ambos os portais, buscou-se como termo a expressão Políticas Curriculares, mas posteriormente necessitou-se a utilização de um filtro mais específico, a fim de concentrar o tema do estudo. Na busca realizada no Portal Scielo, com o termo "Políticas Curriculares", foram encontrados 7514 trabalhos publicados. Após a utilização do filtro para busca "Políticas Curriculares Ensino Superior Pedagogia", foram encontrados 133 pesquisas, das quais foram selecionadas 05 para o presente estudo.

Igualmente realizou-se o mesmo procedimento para o portal Capes Periódicos, e com o termo "Políticas Curriculares" foram encontrados 531 resultados, que diminuíram para 59 quando adicionou-se o filtro "Políticas Curriculares Ensino Superior Pedagogia". Destes foram selecionados 03 para esta pesquisa.

Desta maneira, serão apresentadas as discussões de 08 pesquisas relacionadas intimamente com as Políticas Curriculares do Ensino Superior da Pedagogia.

Após a fase de levantamento de pesquisas realizadas, pretende-se neste momento apresentar os trabalhos selecionados e buscar de fato conhecimentos pertinentes ao desenvolvimento desta pesquisa. Para tanto, as produções serão apresentadas e estudadas por meio de uma mesma lógica, percebendo-se o problema da pesquisa, o método utilizado e os principais eixos teóricos estudados.

\footnotetext{
${ }^{1}$ http://www.scielo.org/ Acesso em: 28 de nov. 2015

${ }^{2}$ www.periodicos.capes.gov.br/ Acesso em: 28 de nov. 2015
} 


\title{
2 ESTADO DA ARTE REALIZADO COM O EIXO TEMÁTICO: POLÍTICAS CURRICULARES ENSINO SUPERIOR PEDAGOGIA
}

Pelo portal Scielo, foi selecionada a pesquisa "Diretrizes Curriculares do Curso de Pedagogia no Brasil: Disputas de Projetos no Campo de Formação do Profissional da Educação" (AGUIAR et. al., 2006, p.819). Esta pesquisa teve como objetivo analisar as novas políticas curriculares do curso de pedagogia, evidenciando alguns problemas que marcaram a história da educação brasileira, à luz do acervo de conhecimentos teórico-práticos sistematizados por entidades do campo educacional, como ANFOPE, ANPED, CEDES, FORUMDIR e ANPAE. Focalizam o movimento dos educadores pela definição das diretrizes curriculares para a formação dos profissionais da Educação Básica.

\begin{abstract}
A problematização das diretrizes concorre para ampliar a compreensão da complexidade do campo da pedagogia e dos desafios teóricos-práticos com que as instituições de ensino superior, em particular as universidades, deparam-se para materializar a reforma do curso de pedagogia, na esteira das novas regulamentações legais e na perspectiva de uma formação cidadã. (Aguiar (2006, p.820)
\end{abstract}

A pesquisa destaca historicamente a luta do curso de pedagogia, desde as diversas interpretações atribuídas as curso no Brasil, como a concepção de licenciatura separada do bacharelado. Também pontual que a história do curso expressa abordagens teórico-práticas, conteúdo-forma e objeto sujeito, reportando-se às questões epistemológicas e sociais.

Quanto às políticas educacionais, levantam a normatização das bases curriculares dos cursos de graduação, declarando que estas estão em conflito permanente e traduzindo perspectivas diferenciadas.

Foi realizada uma vasta pesquisa sobre as várias legislações e regulamentações para a construção das diretrizes de formação do pedagogo, apresentando detalhadamente os projetos de lei, reuniões, debates, encontros e aprovações no que tange estas políticas.

Ao final sugere Aguiar (2006) outros desafios para o campo estudado, como as modificações necessárias no âmbito da formação dos educadores profissionais da educação, entre as quais se pode destacar a inclusão no texto da Lei da Reforma do Ensino Superior, do papel da Universidade e das faculdades, dos centros de educação e departamentos de educação, na formação dos educadores, professores e profissionais da educação básica.

Outra pesquisa selecionada no portal Scielo foi a de Libâneo (2006, p.843), intitulada Diretrizes Curriculares da Pedagogia: Imprecisões Teóricas e Concepção Estreita da Formação Profissional de Educadores. Esta teve como objetivo debater em torno da natureza do conhecimento pedagógico, do curso de pedagogia, dos cursos de licenciatura para a formação de professores e do exercício profissional de professores e especialistas em educação, por meio da Resolução do Conselho Nacional de Educação, CNE, que instituiu as Diretrizes Curriculares Nacionais para os cursos de graduação em pedagogia.

O artigo expõe críticas ao documento, apontando antigos problemas, como as conceituações com relação ao campo pedagógico, que pouco avançam na promoção da melhoria qualitativa das escolas de educação básica, onde estas concepções levariam a outras opções curriculares para a formação profissional de educadores.

Após apresentar os conflitos nas conceituações da Diretriz, com os autores contemporâneos, apontamos para algumas consequências desta incoerência epistemológica, como 
O curso de pedagogia não pode ser igual a curso de licenciatura para formação de professores de educação infantil e anos iniciais do ensino fundamental - o curso de pedagogia é uma coisa, a licenciatura outra, embora interligados; b) a base de formação do pedagogo não pode ser a docência, pois a base de formação docente é o conhecimento pedagógico; c) todo docente é um pedagogo, mas nem todo pedagogo precisa ser docente, simplesmente porque a docência não é a mesma coisa que pedagogia. (Libâneo (2006, p. 851)

Estas incoerências apresentas pelo autor, produzirão consequências para a formação dos professores e para o funcionamento das escolas. Quanto à formação de professores pontua a limitação da teoria pedagógica, decorrente da descaracterização do campo teórico investigativo. Também o desaparecimento dos estudos de pedagogia nos cursos de pedagogia, pois o professor não precisará mais de fundamentos pedagógicos com relação à sua prática. A superficialidade nos estudos devido ao inchamento das disciplinas no currículo do curso, provocadas pela excessiva superficialidade abordada nos conteúdos e o rompimento da formação do curso de pedagogia de diretores, coordenadores pedagógicos e para a pesquisa.

Para o funcionamento da escola, o texto das Diretrizes prejudicam pois, rebaixam a qualidade do ensino, aumenta a responsabilidade da escola quanto à formação cidadã e nas mudanças comportamentais na juventude, afetando a forma de aprender.

Por fim, explicita que é preciso integração entre as três dimensões da pedagogia, oferecendo o bacharelado, a licenciatura em educação infantil e a licenciatura em anos iniciais do ensino fundamental. Estas, fundadas em tradição teórica e saberes da prática, juntamente com as condições históricas atuais, contribuiriam para fornecer elementos para as Diretrizes Nacionais para os cursos de Pedagogia, na crença do poder social e político da escola.

Neste mesmo caminho, a professora Scheibe (2007) constrói uma reflexão sobre as Diretrizes e Bases da Educação Nacional de 1996, por meio da pesquisa Diretrizes Curriculares para o Curso de Pedagogia: Trajetória Longa e Inconclusa.

O foco é no processo de mobilização e resistência das entidades do campo educacional no sentido de assegurar a docência como base e superar a dicotomia entre licenciatura a bacharelado. Para tanto debate quanto a contraposição do modelo de formação dos Institutos Superiores de Educação e de Cursos Normais Superiores, veiculados pela reforma educacional da década de 1990, o qual se insere em um contexto de políticas neoliberais, como a identidade do curso de pedagogia e sua finalidade profissionalizante, instituída como licenciatura.

Ao longo da exposição a autora relata sobre o texto e direcionamentos das novas Diretrizes, que propõe que os Institutos Superiores de Educação disponibilizem cursos formadores de profissionais para a educação básica, podendo desta maneira este profissional pode fazer tudo que um licenciado em Pedagogia pode fazer, só que de maneira mais rápida e barata.

A pesquisa desenvolve-se apresentando que sugestões e propostas foram construídas por uma comissão de Especialistas/SESU/MEC em 1999, nomeada pelo próprio MEC, mas que as sugestões não foram incorporadas nos posteriores documentos. Em 2005, o MEC apresentou uma minuta das novas Diretrizes, o que, segundo a pesquisa, foi "amplamente rejeitado pela comunidade acadêmica" (Schibe (2007, p. 53). Para tanto houve uma mobilização de educadores, sintetizadas em documentos assinados pela Anfope, Anped e Cedes, e encaminhados ao Conselho Nacional de Educação, pois esta minuta apresentou diretrizes para o curso de Pedagogia como licenciatura, dividindo-o em duas habilitações, sendo Magistério da Educação Infantil e Magistério dos anos iniciais do ensino fundamental.

Por fim, coloca que o movimento dos educadores quanto à formação de institutos foi de resistência. 
Com base no esforço pela superação de uma organização educacional inserida predominantemente no contexto das politicas neoliberais, as entidades educacionais já apontadas contrapuseram à racionalidade técnica e à inclusão de natureza sobretudo formal das políticas públicas em construção, princípios para um desenvolvimento crítico social. (Scheibe (2007, p.59)

Mesmo após os debates, posicionamentos e conquistas, ainda existem muitas questões a serem discutidas, como o grau de autonomia e flexibilização dos projetos políticos pedagógicos perante a constituição dos cursos, ou que critérios serão necessários para assegurar a certificação dos trabalhos possíveis de serem realizados pelo licenciado em Pedagogia.

Diante do cenário existente na Educação Básica, e na formação superior dos Professores desta Escola, Gatti (2013) levanta questionamentos sobre o papel dos professores face às demandas socioculturais que lhe são impostas, pois existe uma precariedade na formação destes, e sinaliza que existe a necessidade de uma revolução a fim de reestruturar as dinâmicas curriculares da formação de Professores para a Educação Básica.

Após breve explanação, a autora ainda enfatiza a crise por meio de vários outros autores.

Assim, muitos autores (PEREIRA, 1999; LESSARD; TARDIFF, 2004; AGUERRONDO, 2006; FANFANI, 2007; VAILLANT, 2008) sinalizam a crise, praticamente mundial, no que concerne aos modelos de formação de professores para a educação básica. Crise no sentido de que fortes questionamentos são colocados quanto a essa formação. Crise porque novas demandas são postas a esses trabalhadores que lidam com a formação do humano e, neste sentido, as tensões não são poucas. (Gatti $(2013$, p.52)

Em pesquisas, Gatti (2013) constatou que há grande dissonância entre os Projetos e a estrutura das disciplinas nos cursos de Pedagogia; o currículo para a formação de professores é fragmentada com disciplinas dispersas e fragmentadas; a proporção de carga horária para disciplinas referentes à formação profissional docente com outros tipos de conteúdos, chegando ao extremo de $10 \%$ e $90 \%$ respectivamente; falta de associação entre teoria e prática, percebida nas ementas pesquisadas; falta do currículo da educação básica nas formações; falta de esclarecimento sobre estágios, orientações, acompanhamentos e avaliações; ementários vagos em disciplinas práticas; disciplinas com nomes e ementas redundantes e pouco claras; falta de especificações nas disciplinas de Atividades Curriculares, Seminários ou Atividades Culturais; e, formação precoce de conteúdos que poderiam ser trabalhados em pós-graduação, que visam a formação de outro profissional que não o professor.

Após estes apontamentos, a pesquisa apresenta algumas proposições, como que a formação de professores deve ser pensada e realizada a partir da função social, ensinando o conhecimento acumulado e consolidando valores; formação voltada para a ação pedagógica na educação escolar de crianças e adolescentes; ser inovador nos modelos formativos, com inspiração na concepção atual de ciência.

Em suas considerações finais, a autora aponta que

É preciso integrar essas formação em propostas curriculares articuladas e voltadas a seu objetivo precípuo, com uma dinâmica nas instituições de ensino superior mais proativa e unificada. [...] é necessário que haja "uniformidade de formação de professores" com uma base formativa comum a todas as modalidades e níveis de ensino, base esta, tão defendida desde muito tempo pela Associação Nacional de Formação de Profissionais da Educação (ANFOPE), sendo disto testemunha documento de 1992, em termos reiterados até documentação recente. (Gatti, 2013, p.64) 
A pesquisa levanta, assim como as outras já comentadas, que as políticas e práticas pertinentes à formação do professor para educação básica necessitam urgente de uma reforma, considerando-se as profundas mudanças da sociedade.

Outra pesquisa analisada é sobre As licenciaturas e as novas políticas educacionais para a formação docente de Pereira (1999). Ela discorre sobre questionamentos que envolvem a Lei de Diretrizes e Bases da Educação Nacional, LDB - lei n 9.394/96.

Expõe que até a década de 1990, as licenciaturas estavam sem alterações significativas desde a década de 1930. Também descreve o cenário do país em que a nova LDB foi aprovada. Este cenário apresenta uma América Latina permeada pela atmosfera hegemônica de políticas neoliberais, de interesse do capital financeiro, impostas por intermédio de agências como Banco Mundial e Fundo Monetário Internacional (FMI), "que procuravam promover a reforma do Estado, minimizando o seu papel, e favorecer o predomínio das regras do mercado, incluindo as atividades educacionais". (Pereira (1999, p.111)

Além destas forças financiadoras, também apresenta que na época, as condições para a profissão docente, como o aviltamento salarial e a precariedade do trabalho escolar, desestimulando o jovem escolher a profissão docente.

Apresenta alguns modelos de formação docente, e discute as características de cada uma, como o modelo da racionalidade técnica, que o professor é visto como um técnico que aplica as regras que derivam do conhecimento científico e do conhecimento pedagógico. Conforme o autor, este modelo "mostra-se inadequado à realidade da prática profissional docente" (Pereira $(1999$, p.112). O estudo também aponta que este modelo é o mais identificado em cursos de Licenciaturas em instituições particulares e faculdades isoladas. Para a autora, outro modelo apresentado é o modelo de racionalidade prática, onde o professore é considerado um profissional autônomo, que decide e cria suas próprias ações pedagógicas. Este modelo considera que a prática não é o locus da aplicação de um conhecimento científico e pedagógico, mas um espaço para reflexão e criação.

Um terceiro modelo é apresentado pelo autor, com características dos outros dois, sendo estes balanceados, onde a prática é entendida como eixo para preparação do professor. Mas expões que este modelo também possui várias fragilidades, como o cuidado no planejamento e na intencionalidade das atividades e cargas horárias destas práticas, ou, o descuido com o embasamento teórico na formação.

Por fim, apresenta uma alternativa discutida em eventos na Universidade Federal de Minas Gerais, onde a pesquisa deve ser a protagonista da formação docente, juntamente com a formação inicial e a formação continuada. Defende que estas ações irão desenvolver uma nova cultura institucional dos cursos de formação de professores, de maneira mais qualitativa, a fim de debaterem sobre os desafios propostos pela nova conjuntura política e sociocultural brasileira, em um processo de construção do conhecimento.

Conforme já exposto, foram realizadas pesquisas em diferentes bibliotecas virtuais a fim de levantar estudos feitos no campo da Politicas Curriculares para o Ensino da Pedagogia. Desta maneira, serão apresentados quatro trabalhos selecionados na biblioteca da Capes Periódicos.

Um destes textos selecionados foi o Reforma dos cursos de formação de professores: relações entre as políticas curriculares e a prática pedagógica, de autoria de Zenilde Durli, Elton Luiz Nardi e Marilda Pasqual Schneider. O estudo apresenta debates entre dois campos, sendo o discurso oficial e o pedagógico, discutindo a LDB de 1996 com autores que defendem a não verticalização do Estado em relação aos estudos sobre as políticas curriculares, e a proposta de cursos de licenciaturas na Universidade do Oeste de Santa Catarina. 
No campo oficial, os autores discorrem sobre a conceituação de campo, sob o olhar de Bourdieu, e esclarecem que "a noção de campo se refere a um espaço relativamente autônomo de forças e lutas, permeadas e permeáveis às relações de poder e controle" (Durli, Nardi \& Schneider (2009, p. 332).

Diante disto, consideram que o campo da prática pedagógica é um espaço de descontextualização e recontextualização dos textos oficiais, pois estes sofrem transformações antes de serem apreciados na prática, caracterizando a recontextualização, podendo até modificar alguma interpretação de prioridades, produzindo novos significados.

Estas elucidações, conforme comentam os autores, auxiliaram a pesquisa no que tange as políticas curriculares, tomar o Governo, o Estado e a Prática Pedagógica como agentes desta recontextualização.

A materialização destas construções é a reorganização dos currículos dos cursos de Licenciaturas da Universidade do Oeste de Santa Catarina. Esta nova proposta contemplou "a articulação entre conhecimentos básicos de formação e conhecimentos específicos da área de atuação do profissional; a docência como base de formação; a investigação, entendida como instrumento de ensino e aprendizagem e de difusão do conhecimento; e, a prática de ensino e gestão escolar" (Durli, Nardi \& Schneide (2009, p. 336).

Os autores consideram ao final que as políticas curriculares são construídas por meio de múltiplas realidades e contextos. Que estes textos manifestam a complexidade do processo das políticas curriculares para a prática pedagógica, e os limites de cada um em resinificar.

$\mathrm{Na}$ sequencia das análises dos textos selecionados, a fim de compreender as contradições das DCNs, Durli, Nardi e Schneider (2009) continua seus estudos, tendo como objeto de estudo a atividade interdisciplinar proposta pelas Diretrizes, no âmbito da prática pedagógica.

Os autores estudam os conceitos de interdisciplinaridade a partir da visão de Leonir e Hasni (2004) que, em uma perspectiva subjetiva, "a base da prática docente interdisciplinar está alicerçada em quatro princípios: a humildade, a coerência, a expectativa e a audácia" (Durli, Nardi \& Schneider (2010, p. 144). A mudança na conduta do educador pautada na sua participação comprometida em um sistema de interação com os alunos.

Confrontando com as Diretrizes, apresenta-se que as mesmas sofreram influência internacional, por meio do Relatório Delors, elaborado pela Unoesc. Nestas orientações, a interdisciplinaridade foi adotada no contexto da mundialização, e na forma de relacionamento entre conhecimentos e disciplinas curriculares. Assim, a interdisciplinaridade é estratégica na formação do educador, sendo relacionada ao desempenho do professor e de seus alunos na Educação Básica, estando presente no texto do Parecer CNE/CP 009/2001, onde a avaliação do processo de aprendizagem será realizada na capacidade diagnosticar o uso funcional e contextualizado dos conhecimentos.

Continuando o debate sobre as influências de agências internacionais na construção das políticas públicas de formação de professores, as autoras Casagrande, Pereira e Sagrillo (2014) apresentam uma análise documental da interferência do Banco Mundial nestas políticas, gerando uma agenda global para a educação.

A pesquisa apresenta a lógica dos ajustes comandados pelas agências internacionais, sendo uma continuidade no desenvolvimento multissensorial e no investimento em capital humano como fórmula para aumentar a produtividade da mão de obra e elevar os padrões de aprendizado dos alunos mais pobres da Educação Básica.

Todos estes direcionamentos auxiliarão uma reforma do Estado brasileiro para um contexto de globalização, ajustando este ao mercado mundial, obedecendo às agências internacionais que comandam o processo. Nesta realidade, as autoras afirmam que "a reforma 
do Estado brasileiro foi resultado da difusão das políticas de ajuste do Banco Mundial e dos Planos de Estabilização do FMI. Os empréstimos para os ajustes [...] se constituíram em regras e condicionamentos, particularmente para a Educação Básica" (p.496).

Visualizando a educação como agente do crescimento econômico, o BM está cada vez mais priorizando os projetos referentes à Educação Básica. Esta preocupação tem como objetivo a flexibilização da produção e reestruturação das ocupações, integrada aos setores de produção, exigindo multifuncionalidade e polivalência dos trabalhadores. Este cenário construirá uma Educação Básica mínima, funcional e de baixo custo.

Como exposto, o interesse do BM na Educação Básica, faz com que o mesmo produza e determine políticas para a formação de professores.

Nessa perspectiva, os professores assumem para o Bird uma posição secundária e são até responsabilizados pela má qualidade da Educação Básica. Como sempre, os recursos humanos são os maiores problemas de uma empresa, pois há as questões de aumento de salário, sempre impertinentes, e greves. [...] Então deve-se trabalhar para que a educação dependa o mínimo possível de recursos humanos. (Casagrande, Pereira e Sagrillo (2014, p. 500)

Neste horizonte, a infraestrutura é mais importante para as políticas do BM do que o professor, pois este é considerado um problema, e não uma solução, justificando o posicionamento do professor como secundário, visualizando o professor deslocado da pedagogia.

A partir deste entendimento, o BM condiciona as políticas a não terem financiamentos para as formações docentes e para o escasso dinheiro envolvido, justificando mais uma vez o modelo pedagógico baseado na incorporação de "competências" (p.502).

Coraggio (1996, p. 101 apud Casagrande, Pereira e Sagrillo (2014, p. 502) escreve que "O banco sabe que é preciso capacitar o docente, mas mediante programas paliativos em serviços (se possível a distância), porque não é eficiente investir mais na sua formação prévia."

Diante disto, as instituições formadoras tendem a racionalizar, adequar e otimizar, levando o educando e o educador a relacionar a vida e trabalho como objetos de atenção da ação pedagógica, a fim de corresponder às proposições do estado neoliberal, ao transferir a escola da esfera política para a esfera do mercado.

Para o entendimento destas forças hegemônicas, cabe à comunidade escolar desenvolver capacidades cognitivas, afetivas e psicomotoras relativas ao trabalho intelectual, e não ao Estado.

\section{CONSIDERAÇÕES (IN)CONCLUSIVAS}

Almeida (2015) possibilita compreender que os intelectuais são formados por um conjunto de forças atuantes, e que desta forma caracterizam uma forma de hierarquização, subordinação e emancipação, promovendo um conflito e consequentemente movendo o debate, por meio da construção e observação dos fatos com olhares distintos. Assim, as pesquisas construirão as políticas educacionais que afetam a formação de trabalhadores e dirigentes nas instituições governamentais e civis.

Diante deste percurso, Marx responsabiliza a Universidade como responsável pela divulgação e unificação de ideologia, onde a sociedade civil é campo de luta hegemônica. Desta maneira, os intelectuais, que se encontram na sua maioria dentro das Universidades, são os agentes que irão trabalhar com estas pesquisas em políticas educacionais, contribuindo para a vontade coletiva, ou não. 
Neste estudo, a inserção da discussão sobre o Estado é necessária, pois como apresentado, este exerce diretamente funções econômicas e ideológicas. Diante do explanado, é perceptível que vivemos em uma sociedade regulada e praticamente sem classes, pois o Estado é um representante manipulado da classe dominante. Na situação atual posta, o capital monopoliza a cultura, ciência, arte, Universidade, intelectuais, pesquisa, onde o cenário deveria ser contrário, a Universidade revolucionária e independente.

A Universidade tem por papel ético poder construir conhecimentos que possibilitem uma discussão entre as estruturas, setores, e que contribua com conhecimentos independentes e não influenciados, sem tendências de mercado ou interesses. Assim, "as investigações das políticas educacionais não podem ser dissociadas do estudo sobre o Estado". (Almeida (2015, p. 39)

Frente ao breve exposto, a discussão e percepção sobre a formação de professores é de suma importância, pois são estes que irão construir por meio da Educação e de suas políticas públicas as gerações futuras, discutindo, pesquisando e debatendo. Diante disso, estudar a percepção do professor formador de professores é caminho para o entendimento de questões relevantes para uma possível reestruturação das políticas atuais.

Os cursos de formação de docentes vêm sofrendo inúmeras transformações no que tange as novas exigências das leis e diretrizes curriculares, onde as propostas vão desde reestruturação de cursos até a possibilidade do trabalho docente ser por competências. A ênfase da discussão tem estado centrada, em grande parte, nos currículos dos cursos de formação de professores. No cenário educacional brasileiro essa temática ganha repercussão, através da discussão sobre as reformulações curriculares dos cursos de formação docente. Historicamente, desde a criação dos primeiros cursos de Licenciatura no Brasil, nos anos 30 do século $X X$, constatamos uma fragmentação na forma como estes cursos estão organizados, no modelo $3+1$ que gera um descompasso entre as propostas formadoras e a realidade do trabalho dos professores. Esse descompasso caracteriza-se, pela concepção de que o conhecimento de uma área, em específico, é condição primeira para a formação do professor.

$\mathrm{Na}$ verdade ao falarmos sobre formação de professores, estamos trazendo para debate aspectos relacionados às licenciaturas, a concepção de educação, de ensino superior, aos saberes que constituem o magistério. Especificamente nessa proposta de investigação pretendemos deter a discussão sobre as Políticas de Educação Catarinense, mais especificamente, as curriculares associadas e plenamente inseridas a questão da formação que a configuram. Necessitamos como profissionais da educação, de uma identidade própria, não para nos atermos rigidamente a esta identidade e nos fecharmos à dialeticidade e provisoriedade de todo paradigma, mas sobretudo para que possamos ter um referencial coletivo que possa ser inclusive debatido e superado, quando necessário. Nesse sentido, as mudanças estruturais observadas no início desse século, seja política, econômica ou socialmente falando, indicam haver, se não uma ruptura da modernidade, como defendem alguns autores.

Para o velho Marx, todo ponto de partida é um ponto de chegada e todo ponto de chegada é um ponto de partida. Bem, diante da vasta pesquisa realizada nos sites científicos temos algumas considerações a fazer.

No movimento internacional de discussão curricular verifica-se uma acentuada preocupação para que outros valores iluminem às tecnicidades das áreas específicas, principalmente em seu aspecto ético e social e em favor de uma formação universitária que tenha como base uma educação geral. As reformas universitárias e curriculares que estão se processando ultimamente nos diferentes países da Europa e das Américas e, notadamente no Brasil, atestam que a educação superior é prioritária para o desenvolvimento de uma nação, do 
ser humano e vital na produção do saber. Acentuadamente, as discussões curriculares têm apontado para o desenvolvimento de valores éticos, não como outra disciplina, mas como ênfase intencional da formação do aluno e da apreensão e desenvolvimento do conhecimento e da pesquisa, balizados por julgamentos que colocam o bem estar social e a preocupação humana como orientação para a atuação profissional.

As Diretrizes Curriculares apresentam mudanças na forma de ver e entender a formação na graduação. Uma importante mudança explicitada por elas é o entendimento de que os currículos devem incentivar uma sólida formação geral, necessária para que o futuro graduado possa vir a superar os desafios de renovadas condições de exercício profissional e de produção do conhecimento, permitindo variados tipos de formação e habilitações diferenciadas. Outra é a concepção da graduação como uma etapa inicial de formação no processo contínuo de educação permanente e não como um momento de esgotamento dos conhecimentos.

Por meio do estudo das pesquisas já realizadas, a fim de não sermos vítimas de nossas próprias manipulações quanto pesquisadores, cada vez mais fica claro as orientações de entidades financiadoras internacionais nas ações do Estado, a fim de manipular e manter o Estado como Capitalista e Neoliberal. Estas entidades possuem a plena consciência que o controle sobre o acesso e ao conteúdo que constroem a educação em um país, direciona a médio e longo prazo o futuro para que seus próprios interesses sejam concretizados.

Atualmente percebe-se que o interesse destes "parceiros" é a educação para o trabalho, a fim de atender a uma futura mão de obra especializada na produção industrial. Tendo estas agências este objetivo, pode-se sugerir que o interesse em nosso país, rico em matérias-primas, seja apenas uma nação rica em mão de obra e não em profissionais intelectuais. Nesta estrada a ser percorrida, visualiza-se as políticas nacionais incentivando os programas sociais focados na escolarização técnica, como as engenharias, e não em cursos de produção intelectual, como as Licenciaturas, por exemplo.

\section{REFERÊNCIAS}

Aguiar, M. A. S. et al. (2006). Diretrizes Curriculares do curso de Pedagogia no Brasil: disputas de projetos no campo da formação do profissional da educação. Educação \& Sociedade, 27(96), 819-842. Recuperado de http://www.scielo.br/pdf/es/v27n96/a10v2796.pdf

Almeida, M. L. P. ; Silva, S. R. (2015). A perspectiva epistemológica em Antônio Gramsci e a pesquisa de Políticas Educacionais. Educação Temática Digital, 17(1), 27-41. Recuperado de http://www.fe.unicamp.br/revistas/ged/etd/view/6867

Brasil. Ministério da Educação e Cultura. (1996). Lei de Diretrizes e Bases da Educação Nacional: n. 9394/96. Brasília: MEC.

Casagrande, L. M. K., Pereira, S. M. e Sagrillo, D. R. (2014). O Banco Mundial e as políticas de formação docente no Brasil. ETD, 16(3), 494-512. Recuperado de https://www.fe.unicamp.br/revistas/ged/etd/article/view/6700

Connor, S. (1992). Theory and Cultural Value. Oxford: Blackwell.

Durli, Z. ; Nardi, E. L. \& Schneider, M. P. (2009). Reforma dos cursos de formação de professores: relações entre as políticas curriculares e a prática pedagógica. Educação, 32 (3) 331-338.

Recuperado

de http://revistaseletronicas.pucrs.br/ojs/index.php/faced/article/viewFile/4946/4189

Ferreira, N. S. A. (2002). As pesquisas denominadas "Estado da Arte". Educação e Sociedade, 23(79), 257-272. Recuperado de http://www.scielo.br/pdf/es/v23n79/10857.pdf 
Gatti, B. A. (2015). Educação, escola e formação de professores: políticas e impasses. Educar em Revista, 50(05), 51-67. Recuperado de http://www.scielo.br/pdf/er/n50/n50a05.pdf

Libâneo, J. C. Diretrizes Curriculares da Pedagogia: imprecisões teóricas e concepção estreita da formação profissional de educadores. Educação \& Sociedade, 27(96), 843-876. Recuperado de http://www.scielo.br/pdf/es/v27n96/a11v2796.pdf

Pereira, J. E. D. (1999). As licenciaturas e as novas políticas educacionais para a formação docente. Educação \& Sociedade, 20(68), 109-125. Recuperado de http://www.scielo.br/pdf/es/v20n68/a06v2068.pdf

Scheibe, L. (2007) Diretrizes Curriculares para o curso de Pedagogia: trajetória longa e inconclusa. Caderno de Pesquisa, 37(130), 43-56. 3Recuperado de http://www.scielo.br/pdf/cp/v37n130/04.pdf

Schneider, M. P. (2010). A organização interdisciplinar na reforma curricular da formação docente. Educação, 35(1), 139-154. Recuperado de http://cascavel.ufsm.br/revistas/ojs2.2.2/index.php/reveducacao/article/view/1371 